\title{
Editorial Introduction to the Cluster on Foreigners in Philosophy
}

The articles in this cluster address a topic that philosophers have only recently begun to discuss: foreigners in philosophy. A conference on this subject, organized principally by Saray Ayala-López, took place on March 29, 2016 at the University of California, Berkeley. We at Hypatia were pleased to fund the conference with a Hypatia Diversity Project grant and are further pleased to publish pioneering work on the subject.

A passage on the homepage of the conference website https://foreignersinphiloso phy.weebly.com/ illuminates some of the reasons that work on this topic is needed:

There is a dimension of diversity and inclusiveness that has not been addressed in our profession yet: the aspect of being a foreigner, i.e. a person who, given their country of origin and/or native language(s), is considered "non-native" in the location where they work or study. The category of foreigner is ripe for philosophical exploration. Given the dearth of literature on how being a foreigner interacts with the practice of philosophy, and the lack of understanding of how the category of foreigner intersects with other socially relevant categories like gender, race, disability, socioeconomic status and sexual orientation, this workshop will open new ground and expand our efforts to make our profession more inclusive.

Readers can find a number of resources on the conference site: the program for the conference (including lengthy abstracts and PowerPoint presentations of some of the talks presented), additional resources on relevant topics, links to the blog "What Is It Like to Be a Foreigner in Academia?" https://beingaforeignerinacademia.wordpress. $\mathrm{com} /$ and to other essays, and more.

The three essays here help us start thinking in new and subtle ways about a number of related topics: what it is both conceptually and experientially to be a foreigner in philosophy; the positive impact that foreigners can have on philosophy; the need for social justice for foreigners in philosophy and strategies for trying to achieve it; the interactions among one's identity as a foreigner and other important social categories; and the role that the English language plays in shaping philosophy.

Let us cite just a few themes from the essays as examples. Verena Erlenbusch explores the meanings of different kinds of foreigners-linguistic, material, cultural, and epistemic — and explains what foreigners have to offer philosophy in the "culture 
of justification" (Salamon 2009; Dotson 2012) in which philosophy published in English is entrenched. Ayala-López develops categories of foreigners that are not reducible to other socially important categories such as ethnicity, class, or race, but intersect with them in complex ways. Using this analysis, Ayala-López explores both the "peculiarities" of foreignness and the "moderators" of it and argues that foreigners should be targets of diversity and inclusivity efforts. Elif Yavnık presents detailed analyses of a central experience of foreigners - existential dislocation - and discusses implications of existential dislocation for practicing philosophy and for equality in the academic world.

We hope that these essays will motivate philosophers and others to pursue the many fascinating issues that cluster around the topic of foreigners in philosophy.

\section{REFERENCES}

Dotson, Kristie. 2012. How is this paper philosophy? Comparative Philosophy 3 (1): 3-29.

Salamon, Gayle. 2009. Justification and queer method, or leaving philosophy. Hypatia 24 (1): $225-30$. 